\title{
From Mechanical Spraying to Electrospraying-Advanced Technology Teaching in Higher Education
}

\author{
Yonghui $\mathrm{Wu}^{1, \text { a }}$, Hanfang $\mathrm{Li}^{2}$, Jing $\mathrm{Ma}^{2}$, Jinxin $\mathrm{Xu}^{2}$, Dengguang $\mathrm{Yu}^{2, \mathrm{~b}, *}$ \\ ${ }^{1}$ The Department of Mechanical Engineering, Guangxi Technological College of Machinery and Electricity, \\ Nanning 530007, China \\ ${ }^{2}$ School of Materials Science \& Engineering, University of Shanghai for Science and Technology, Shanghai 200093, China \\ aahuiwyh@163.com, bydg017@usst.edu.cn \\ *Corresponding author
}

\begin{abstract}
It is important to explain the advanced nanotechnology to the college students in higher education for training their creativity and arousing their learning interests. In this paper, a new method was developed for teaching the new technology in a vivid manner. The results demonstrated that an analogical comparison between a traditional technique and an advanced one not only can effectively promote the students to understand the new one, but also can be used as a useful tool to encourage the student to do more self-learning about material science and engineering in higher education. With electrospraying as a technique model, the difficulties in clear explanations this complicated new process in the class could be easily overcome by the usage of traditional spraying as a start point. Based on their past knowledge and experience about the spraying processes, the college students majoring in material engineering were able to quickly grasp the essences of electrospraying, discriminated the differences between electrospraying and spraying. Some students eagerly went to the experimental laboratory to carry out some experiments about the preparations and characterizations of electrosprayed protein microparticles.
\end{abstract}

Keywords-Higher education; Material engineering; Electrospraying; Spraying; Analogical teaching

\section{INTRODUCTION}

Technology always acts as a vital element of teaching materials for the college students in high school, who major in the subject of Material Science and Engineering [1-3]. The interdisciplinary field of materials science and engineering involves the discovery and design of new materials, and what is important is the technologies exploited to create these new materials. From an engineering standpoint, a material cannot be used in industry if no economical production method for it has been developed [4]. Thus, the material processing technologies are very important in the field of materials science and engineering [5], which should be taught to the high school students as far as possible.

Shown in Fig.1, when a new desired product is needed, it first needs to be designed and the start crude materials should be carefully selected. Later, the material processing technology, which includes a single step or consists of a series of material processing and transferring processes, will play its role in converting the crude materials to the designed products. The products must be subjected a series of characterizations and analysis before it can be utilized as commercial products for commercial applications. Certainly, the material science theories will play a fundamental role during all these conversion and analysis processes.

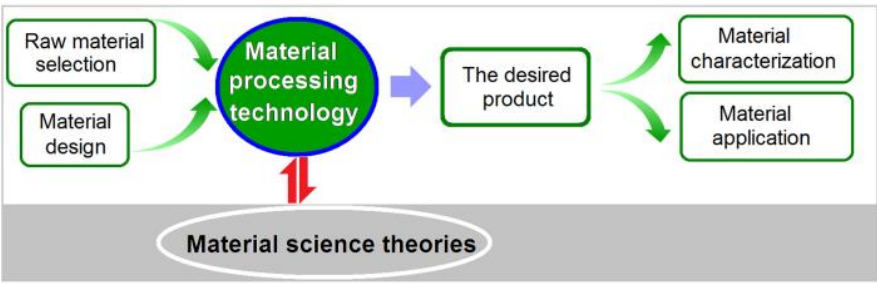

Fig. 1. Material processing technology acts as a key element in the practical teaching system of Material Science and Engineering

The material science and engineering is very broad field with different materials require different processing technologies. For example, the processing of metals has historically been very important and is studied under the branch of materials science named physical metallurgy. As of the early 21 st century, new methods are being developed to synthesize materials at micro-scale. Thus in this paper, a popular and advanced nanotechnology--electrospraying is selected as an example to show how to explain clearly to the college students in higher education, with a traditional technology--spraying as a reference.

\section{TRADITIONAL SPRAYING AND THE ADVANCED ELECTROSPRAYING}

Analogical comparison is a very useful way for explaining new meaning to the college students of material processing technology through comparing their known knowledge to the unknown one $[2,3]$. Here, to the college students majoring in Materials Science \& Engineering, the traditional spraying is known and advanced electrospraying is unknown to them.

Shown in Fig. 2 is a typical processes of the traditional spraying technology for preparing particles. The system is 
complicated to include a series of components such as air compressor, filter, storage pot, heater, liquid pump, a series of gas fans, and whirl separator. However, the key concept is that the spraying is a material processing technology, which starts from a working dope and ends in a product of solid powders. The produced fibers often have a diameter at the macro-scale [6, 7].

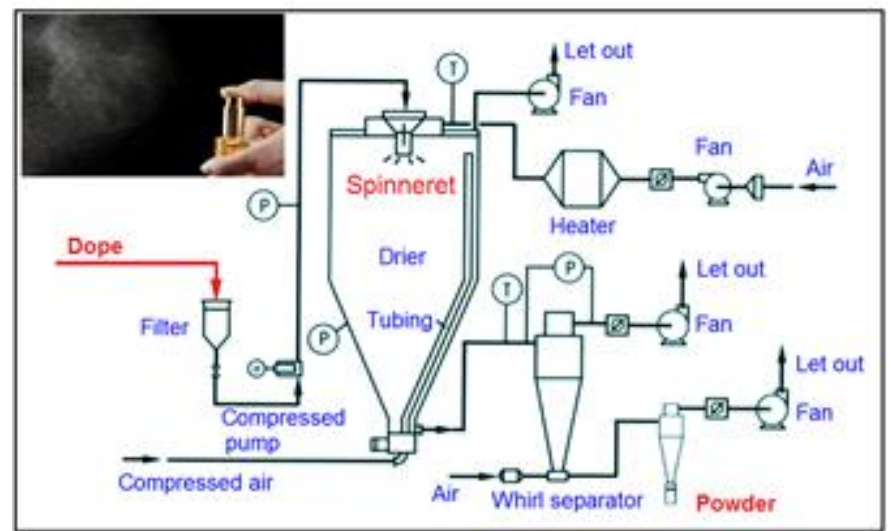

Fig. 2. A schematic diagram of the traditional spraying processes for creating particles, the inset showing a typical spraying of perfume.

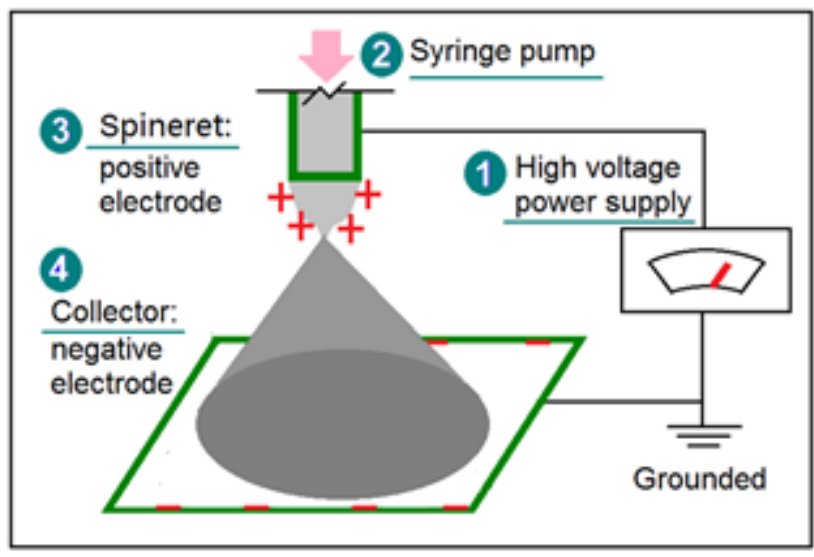

Fig. 3. A schematic diagram of the electrospraying process.

The electrospraying process is a relatively simple process, just as the popular electrospinning process [8-17]. A diagram is shown in Fig. 3. It is a useful technology for preparing the particle-based materials at the micro-scale, such as polymeric micro-particles, protein micro-particles and their composites in a "top-down" manner [18, 19]. An electrospraying system is often composed of four components, i.e. the high-voltage power supply, the working fluid driving pump, the spinneret and the particle collector [20-23]. The technique essentially involves making a solution of a solute or a mixture in a volatile solvent, and ejecting this from a syringe fitted with a metal needle (the spraying head). A high potential difference is applied between the spraying head and a grounded collector. In a typical electrospraying process, a liquid is fed to a metal capillary at the end of which a droplet is formed. When the droplet is exposed to a strong electric field, a charge is induced on its surface. Provided the liquid has sufficient electrical conductivity, there will be a range of combinations of the liquid flow rate and the applied voltage for which the drop will assume a conical shape (the Taylor cone). At the apex of this cone, a narrow jet is formed (cone-jet mode) which subsequently breaks up into fine droplets (Fig. 3). Electrospraying first generates near-monodisperse droplets whose size can be varied between a few to hundreds of micrometers. Later, the droplets rapidly shrink due to the fast evaporation of solvents resulting from the Coulombic explosion (Fig. 3). The huge surface areas of the micro-droplets provide the possibility for complete of the solvents and the solidification of products. The facile interactions of electrons with fluid solvents accelerate their evaporation. If the solvent evaporates well, the droplets shrink, and finally solid particles are formed, a typical electrospraying is shown in Fig. 4, in which the atomization is obvious after the Taylor cone.

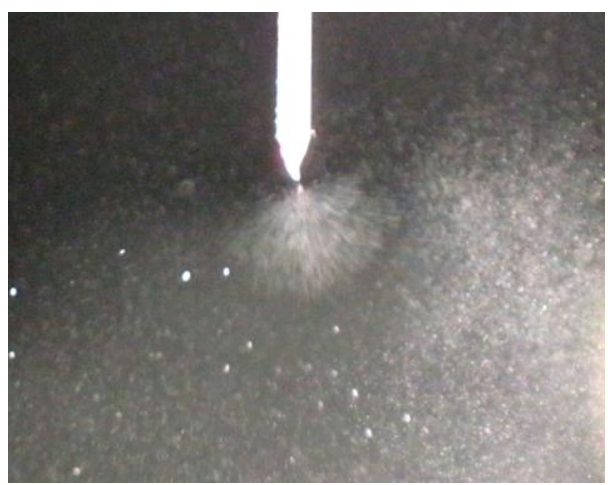

Fig. 4. A digital picture of a typical electrospraying process, in which the working fluid is a protein solution.

\section{COMPARISON FOR EFFECTIVE TEACHING THE NEW TECHNOLOGY}

A detailed comparisons of the spraying technology and the electrospraying are included in Table 1 for the students to effectively understand the meaning of the advanced nanotechnology from the traditional one. They are similarities in the following aspects: 1) Both belong to granular formation technology; 2) And thus both start from liquid solutions and their final products are similarly solid materials; 3) To fulfill the goal, both comprise the similar four parts, the fluid driving and measuring systems, the atomization force systems, the particulate collection systems and the spraying head.

However, Table 1 has listed the major differences between these two particle-forming techniques. First, their fundamental mechanisms are different, one by electrical forces and the other through mechanical atomization. Second, under their different mechanisms, their apparatuses are different, for example, one using aluminum foil as collector to taking advantage of its conductivity and the other using whirl separator; one using syringe pump to drive and measure the fluid volumes and the other often using compressing air. Third, their working fluids often have different concentrations and comprise different solvents. Forth and the most important one, their products are different, which determine the electrospraying is an advanced nanotechnology whereas the spraying is a traditional particle-forming technology. The electrosprayed particles often have a diameter of several nanometers to several microns. Shown in Fig. 5 are scanning electron microscope images of a 
kinds of protein particles from the electrospraying process (Fig. 5a) and the traditional spraying process (Fig. 5b). Obviously, the sprayed particles have a size of several decades of microns, an order of magnitude larger than the electrosprayed products.

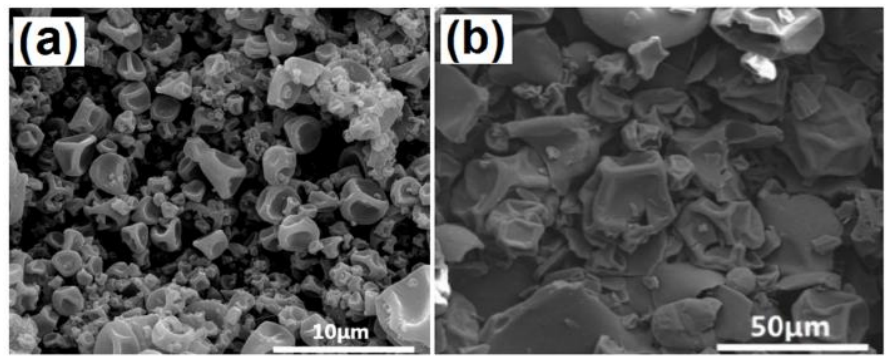

Fig. 5. SEM images of the protein particles from the electrospraying process (a) and the traditional spraying process (b).

TABLE I COMPARISON OF THE SPRAYING AND THE ADVANCED ELECTROSPRAYING

\begin{tabular}{|l|l|l|l|}
\hline \multicolumn{2}{|c|}{ Item } & \multicolumn{1}{|c|}{ electrospraying } & \multicolumn{1}{c|}{ spraying } \\
\hline \multirow{3}{*}{ Working fluid } & Solute & $\begin{array}{l}\text { Solid solute and/or } \\
\text { Functional ingredient }\end{array}$ & $\begin{array}{l}\text { Solid solute and/or } \\
\text { Functional ingredient }\end{array}$ \\
\cline { 2 - 4 } & Solvent & Volatile organic solvent & Common solvent \\
\hline \multirow{2}{*}{ Fundamental mechanism } & $\begin{array}{l}\text { Electrical forces interact with the } \\
\text { working fluids }\end{array}$ & Mechanical atomization and heating \\
\hline \multirow{5}{*}{ System } & Power supply & Typically 0-60 kV & Mechanical forces \\
\cline { 2 - 4 } & Spraying head & Model for nanostructure & Model for leading fluids \\
\cline { 2 - 4 } & Pump & Syringe pump & Compresses air driving \\
\cline { 2 - 4 } & Collector & Aluminum foil & Whirl separator \\
\hline Product & Products at nanoscale & Products at macroscale \\
\hline
\end{tabular}

\section{SUMMARY}

The grasp of advanced modern material processing technologies is very important for the college students majoring the subject of material science and engineering. How to explain clearly the advanced nanotechnology to the college students in higher education in a vivid way is very important for training their creativity and arousing their learning interests. With electrospraying and spraying as models, we explain how to carry out the analogical teaching of advanced technology in higher education. By the usage of traditional spraying as a start point, and based on their past knowledge and experience about the spraying processes, the college students were able to quickly grasp the contents of electrospraying, discriminated the differences between electrospraying and spraying. From traditional technique to advanced technique can comprise an effective method for the college students to learn the unknown knowledge about the advanced techniques from their known experiences about traditional ones.

\section{ACKNOWLEDGEMENTS}

The financial supports from the following projects are appreciated: the Research Project on Vocational Education and Teaching in Guang-Xi Province (GXGZJG2016A028), the Shanghai Education Science Research Project (C17058), the National Natural Science Foundation of China (No. 51373101), the 2016 key project on teachers teaching development in USST (CFTD17017Z), and the College Student Innovation Project of USST (Nos. XJ2017282, SH2017189, SH2017190 and SH2016191).

\section{REFERENCES}

[1] Y.H. Wu, B.W., Qiu, J.Q., Luo, Y.Y. He, X.W. Zhang, S.Y. Zhou, D.G. $\mathrm{Yu}$, "From visible to invisible"-inspiring students' study interests from experimental phenomena. International Conference on Education and Development 2016 (ICED), pp89-94. Nanjing, PR China, Apr 16-17, 2016.

[2] Y.H. Wu, Q.R. Qian, Z. Lin, J.S. Liu, X.W. Zhang, D.G. Yu, Reforms about the teaching of scientific instruments in higher education. Advances in Social Science Education and Humanities Research (Ed. Chen, JM), 73 (2016) 417-421.

[3] X.Y. Li, B.W. Qiu, J. Wan, W.Q. Yu, X.W. Ding, D.G. Yu, Promoting college students to enhance self-learning about quantitative analysis instruments through association. International Conference on Education and Development 2016 (ICED), pp199-203. Nanjing, PR China, Apr 16-17, 2016

[4] Anonymity. https://en.wikipedia.org/wiki/Materials_science, 24-Febuary-2017.

[5] D.G. Yu, D. Wang, S.Y. Zheng, X.Y. Wang, X.H. Chen, H. Sun, Y. Tang, Y.Y. He, To effectively combine the science and engineering teaching in higher education from the scientific phenomena. Advances in Social Science Education and Humanities Research (Ed. Chen, JM), 73 (2016) 756-760.

[6] L. Wang, Q. Fu, N. Liu, J. Sun, Improvement of the adhesion strength of MoSi2-ZrB2 coating by optimizing particle spraying and subsequent heat treatment, J. Therm. Spray Technol., 25 (2016) 1280-1288.

[7] X. Tong, J. Dong, Y. Shang, K. Inthavong, J. Tun, Effects of nasal drug delivery device and its orientation on sprayed particle deposition in a realistic human nasal cavity, Comput. Biol. Med., 77 (2016) 40-48.

[8] G.Z. Yang, J.J. Li, D.G. Yu, M.F. He, J.H. Yang and G.R. Williams, Nanosized sustained-release drug depots fabricated using modified tri-axial electrospinning, Acta Biomater., 53 (2017) 233-241.

[9] G.Z. Yang, H.P. Li, J.H. Yang, J. Wan and D.G. Yu, Influence of working temperature on the formation of electrospun polymer nanofibers, Nanoscale Res. Lett., 12 (2017) 55.

[10] J. Yan, Y.H. Wu, D.G. Yu, G.R. Williams, S.M. Huang, W. Tao and J.Y. Sun, Electrospun acid-base pair solid dispersions of quercetin, RSC Adv. 4 (2014), 58265-58271.

[11] C. Li, Z.H. Wang, D.G. Yu and G.R. Williams, Tunable biphasic drug release from ethyl cellulose nanofibers fabricated using a modified coaxial electrospinning process, Nanoscale Res. Lett., 9 (2014) 258.

[12] D.G. Yu, Y. Xu, Z. Li, L.P. Du, B.G. Zhao and X. Wang. Coaxial electrospinning with mixed solvents: From flat to round Eudragit L100 
nanofibers for better colon-targeted sustained drug release profiles, J. Nanomater., 2014 (2014) 967295.

[13] W. Qian, D.G. Yu, Y. Li, Y.Z. Liao, X. Wang and L. Wang, Dual drug release electrospun core-shell nanofibers with tunable dose in the second phase, Int. J. Mol. Sci., 15 (2014) 774-786.

[14] C. Li, Z.H. Wang and D.G. Yu, Higher quality quercetin sustained release ethyl cellulose nanofibers fabricated using a spinneret with a Teflon nozzle, Colloid. Surface. B, 114 (2014): 404-409.

[15] J. Yan, K. White, D.G. Yu and X.Y. Zhao, Sustained release multiple-component cellulose acetate nanofibers fabricated using a modified coaxial electrospinning process, J. Mater. Sci., 49 (2014) 538-547.

[16] J. Xie, H. Mao, D.G. Yu, G.R. Williams and M. Jin, Highly stable coated polyvinylpyrrolidone nanofibers prepared using modified coaxial electrospinning, Fiber. Polym. 15 (2014) 78-83.

[17] D.G. Yu, X.Y. Li, W. Chian, Y. Li and X. Wang, Influence of sheath solvents on the quality of ethyl cellulose nanofibers from a modified coaxial electrospinning, Biomed. Mater. Eng., 24 (2014) 695-701.
[18] Z.P. Liu, L. Cui, D.G. Yu, Z.X. Zhao, L. Chen. Electrosprayed core-shell solid dispersions of acyclovir fabricated using an epoxy-coated concentric spray head, Int. J. Nanomed., 9 (2014) 1967-1977.

[19] C. Li, D.G. Yu, G.R. Williams, Z.H. Wang. Fast-dissolving core-shell composite microparticles of quercetin fabricated using a coaxial electrospray process, PLOS One, 9 (2014) e92106.

[20] L. Cui, Z.P. Liu, D.G. Yu, S.P. Zhang, S.W.A. Bligh, N. Zhao. Electrosprayed core-shell nanopartciles of PVP and shellac for furnishing biphasic controlled release of ferulic acid, Colloid. Polym. Sci., 292 (2014) 2089-2096.

[21] D.G. Yu, J.J. Li, M. Zhang, G.R. Williams. High-quality Janus nanofibers prepared using three-fluid electrospinning. Chem. Commun., 53 (2017) 4542 - 4545

[22] G. Chen, Y. Xu, D.G. Yu, D.F. Zhang, N.P. Chatterton, K.N. White, Structure-tunable Janus fibers fabricated using spinnerets with varying port angles, Chem. Commun., 51 (2015) 4623-3626.

[23] D.G. Yu, X.Y. Li, X. Wang, J.H. Yang, S.W.A. Bligh, G.R. Williams, Nanofibers fabricated using triaxial electrospinning as zero order drug delivery systems, ACS Appl. Mater. Interfaces, 7 (2015) 18891-18897. 